Changing Futures: Housing and support services for people discharged from psychiatric hospitals. By Don Braisby, Rose Echlin, Steve Hill and Helen Smith. King Edward's Hospital Fund for London. 1988. Pp. 114. £6.50.

"Nothing in this paper is radically new". Agreed. The authors go over well trodden ground, ground trampled flat by others in the rush to denigrate the mental hospital and extol the virtues of community care. The paper assumes that mental hospitals will close and that the 'community' must cope. To their credit, however, the authors recognise many of the pitfalls of resettlement.

The paper is aimed at staff concerned with resettling people discharged from long-stay hospitals and also at those developing housing schemes for people with serious psychiatric disabilities who are already living in hostels or with their families. The paper deals not only with 'bricks and mortar' but with less tangible 'support services'. Throughout the paper the principle of normalisation provides the basis on which services can be evaluated.

The paper is probably best when it concentrates on the bricks and mortar. They suggest that a coordinated service will assess housing needs: staffed homes; multiple occupancy homes; single flats; adult fostering; respite care provision and so on. There should also be provision for crisis support and 'non institutional asylum'. The concept of 'least moves' is a good one. The housing should be dispersed, close to shops and in a quiet neighbourhood. There should be 'move-on accommodation' but the resident should decide when it is time to move on.

The second area examined is support services and here their hopes may not be realised. Crucial to the patients' well-being is the expansion of social networks, the development of skills for living, adequate personal income, and access to crisis care. Can patients develop in this area? Many residents will be chronic schizophrenics with multiple social handicaps.

The process of resettlement should not be a passive experience for the patient. Patients must participate. Both self advocacy and staff advocacy are necessary examples of good practice, e.g. in Holland, are given.

What about the staff? The paper recognises that hospital staff may (will?) feel devalued. Indeed many may have to change jobs. The report suggests that views should be positive and that the advantages of moves should be spelt out; for example, initiative can be used, good working conditions can be obtained, credit can be given for enhanced patient care.

Finally, the paper highlights throughout the need for co-operation. Different groups must work together-housing associations, health authorities, social service departments and voluntary agencies. Griffiths of course has tackled this crucial problem head-on and suggested social service departments should be the co-ordinators of community care. We shall see.

\section{Crichton Royal Hospital} Dumfries

R. G. MCCREADIE

New Directions in Mental Health Care Evaluation. By I. Marks, J. Connolly and M. Muijen, University of London Press, 1988. Pp. 58. Price not stated.

With the forthcoming near simultaneous retirements of Professors Wing, Shepherd and Kreitman, and the impending closure of the MRC facilities at Northwick Park Hospital, centrally funded psychiatric research in Britain faces its severest threat since the Second World War. This booklet reports a meeting held at the Institute of Psychiatry on 3 July 1987 which put forward plans for a health care evaluation unit (henceforth unpronounceably referred to as the hceu) to be set up at the Institute. Perhaps a modest phoenix may survive the inferno.

The meeting was funded by DHSS and the Nuffield Provincial Hospitals Trust, and included representatives of about 15 organisations with an interest in health care evaluation in this country, as well as a powerful American delegation and a single representative from continental Europe. Four papers were delivered (three from the USA, one from the chairwoman of 'Good Practices in Mental Health', none from Europe) and the discussion of each was opened by a distinguished speaker. In brief, the meeting was discussing the proposition that there should be an hceu at the Institute in which there would be full-time staff doing research, teaching and consultation. However, the hceu would link with interested parties outside the Unit to co-ordinate a "consortium'-or network-of researchers interested in health care evaluation. The terms in which members of the consortium would relate to staff in the main hceu were not spelled out in much detail.

Sir Henry Yellowlees mentioned that the impetus for the meeting had come from Joe Connolly and Isaac Marks, who had suggested both the idea of the consortium and the need to include measures derived from health economics. "I invite you to agree," said Sir Henry, "that you are interested in something wider than the actual research you carry out, and to conclude that we are in politics." He reminded his audience that there is at present a lack of political will in this area, and that where there is no political will things do not happen. That, he said, was a hard fact of life. He went on to advise the fledgling hceu to learn how to 'sell itself in the marketplace, and to express itself in terms that a finance officer could understand.

Health economists (who are actually just as bad as we are in expressing themselves in terms totally 